\title{
Electrocatalysts for Low Temperature Fuel Cells
}

\author{
M.V. Martínez-Huerta ${ }^{1} *$ and M.J. Lázaro ${ }^{2}$ \\ ${ }^{1}$ Instituto de Catálisis y Petroleoquímica, CSIC, Marie Curie 2, Cantoblanco, 28049 Madrid, Spain \\ ${ }^{2}$ Instituto de Carboquímica, CSIC, Miguel Luesma Castán, 50018 Zaragoza, Spain \\ *Corresponding author \\ E-mail address: $\underline{\text { mmartinez@icp.csic.es }}$
}

\begin{abstract}
Low temperature fuel cells technologies are currently shifting very fast from fundamental research to real growth. The development of electrocatalysts plays a vital role in the electrocatalytic reactions involved in these devices, because the catalyst determines the overall reaction efficiency, durability and cost. This article review progress in the research and development of electrocatalysts for low temperature fuel cells technologies, with especial attention in the contribution of our research teams over the last 15 years or so. The intensive research efforts in reducing or replacing Pt-based electrodes in fuel cells have been focus in the use of carbon nanomaterials as electrocatalytic supports, including carbon nanostructures tailored by surface modification or building in particular dopants/defects. Recent research effort has also led to the use of electronic conductivity noncarbon support materials. In addition, carbon-composite materials are proving to be a robust, inexpensive and active electrocatalysts, where the synergetic effect between the carbon nanomaterials and the ceramic or polymer nanostructures can lead to a superior electrocatalytic performance and durability for low temperature fuel cells. Perspectives on these catalysts and possible pathways to address current remaining challenges are also discussed.
\end{abstract}

Keywords: electrocatalysts, low temperature fuel cells, carbon nanomaterials, transition metal carbides, composites 


\section{Introduction}

Low temperature fuel cells are among the most promising candidates for the reliable and efficient conversion of hydrogen or alcohol into electric power in automotive, distributed power generation, and portable electronic applications on a large scale [1-5]. The one-step (from chemical to electrical energy) nature of the electrochemical process, in comparison to the multi-step (e.g. from chemical to thermal to mechanical to electrical energy) processes involved in combustion-based heat engines, offers several unique advantages, making them one of the strongest candidates to be the energy conversion device of the future $[2,5]$. Since the development of perfluorinated cation exchange membranes, such as Nafion ${ }^{\circ}$, proton exchange membranes have dominated as the electrolyte for polymer electrolyte membranes fuel cells (PEMFCs) and direct alcohol fuel cells (DAFCs). This electrolyte conducts protons from the anode to the cathode, where the oxygen is reduced to obtain water (Figure 1).

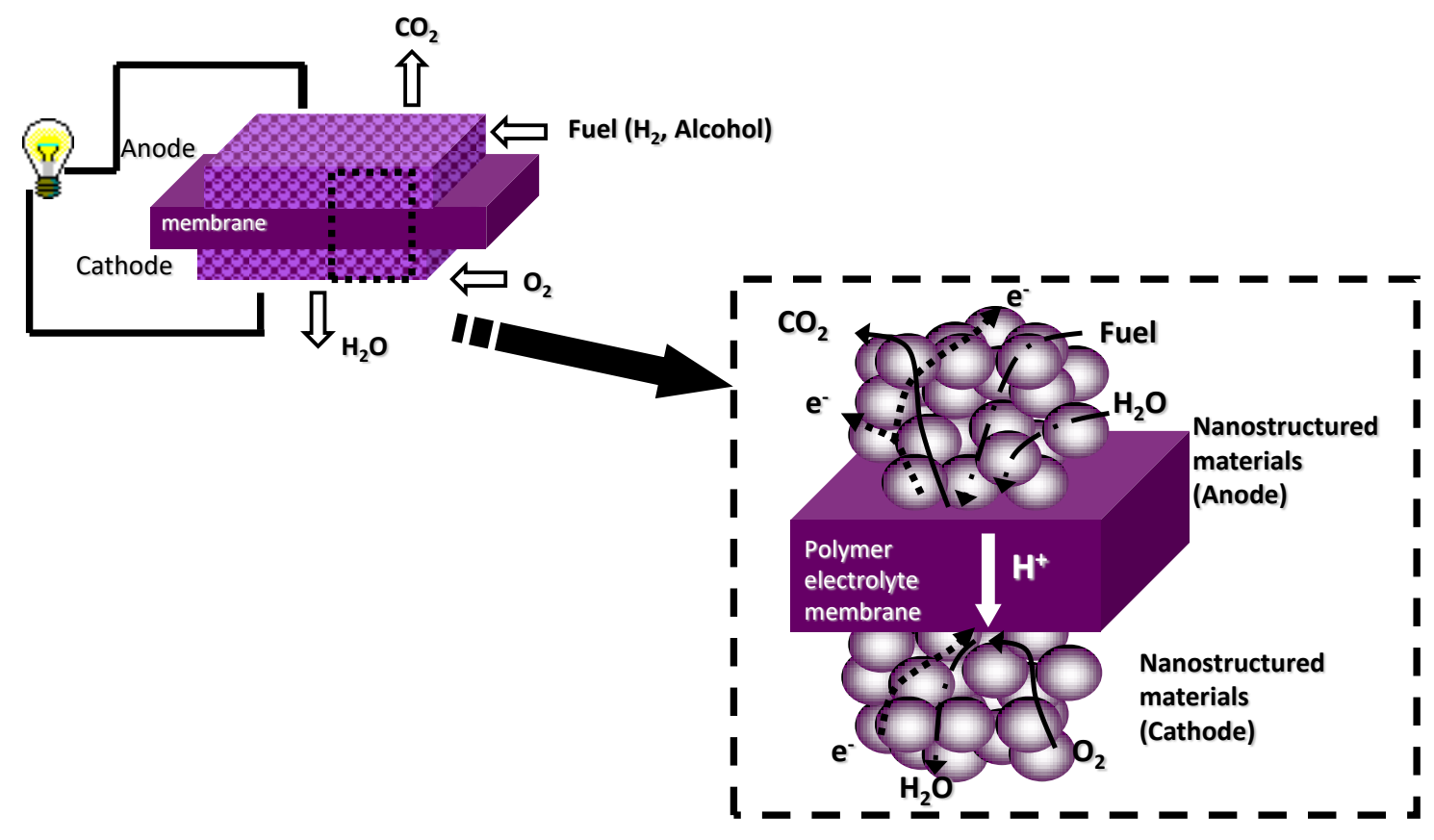

Figure 1 Schematic illustration of a polymeric electrolyte membrane fuel cell (PEMFC) and/or direct alcohol fuel cell (DAFC) 
However, some major obstacles have restrained more rapid development and applications of PEM fuel cells, like the high cost of membranes and noble metal catalysts, and the relatively low activity and complex reaction mechanism, predominantly during the oxygen reduction reaction (ORR) at the cathode. Anion exchange membrane fuel cells (AEMFCs), which oxidize fuel directly on the anode in alkaline media, have attracted attention again in recent years because of the potential solutions to overcome the problems in the PEM fuel cells. As polymer electrolyte membrane fuel cells, anion exchange membrane fuel cells (AEMFCs) have similar structures with PEMFCs $[6,7]$. However, the most important difference between them lies on that AEMFC uses an alkaline polymer electrolyte membrane, which can conduct $\mathrm{OH}^{-}$anions. The AEMFCs present several potential advantages compared to its acidic Nafion-based counterparts, including much improved kinetics of electrochemical reactions, materials stability, and easy water management. Thus, AEMFCs may hold great potential to become the most efficient low-temperature fuel cell in the near future, providing opportunity to use a host of non-platinum group metal catalysts [8-11].

The electrocatalytic processes involved in the low temperature fuel cells can be achieved at temperature lower than $120^{\circ} \mathrm{C}$ and atmospheric pressure, and the reaction rate and selectivity are possibly controllable by using an appropriate electrocatalyst. Therefore, the electrocatalyst play a crucial role in this technology [12]. To play its essential function, an electrocatalyst needs to provide high intrinsic activities for the electrochemical oxidation of a fuel at the anode, whether this is hydrogen or alcohol (methanol, ethanol), and for the electrochemical reduction of oxygen at the cathode. Other requirements include high electrical conductivity, appropriate physical and electrical contact with the ionomer, suitable reactant/product gas access/exit, and high stability in the highly corrosive working medium $[13,14]$. To ensure that a fuel cell 
delivers maximum efficiency, both electrode reactions need to take place close to their thermodynamic potential as possible.

The oxygen reduction reaction (ORR) is the primary electrochemical reaction occurring at the cathode of low temperature fuel cells, and is central to these technologies because is the main source of efficiency losses [2, 15]. Oxygen is converted to water at the cathode via the oxygen reduction reaction with two possible reaction routes: the direct four-electron pathway and the two-stage pathway with two electrons transferred in each stage and a peroxide intermediate (Scheme 1)

\section{Oxygen Reduction Reaction}

\section{Acid electrolyte}

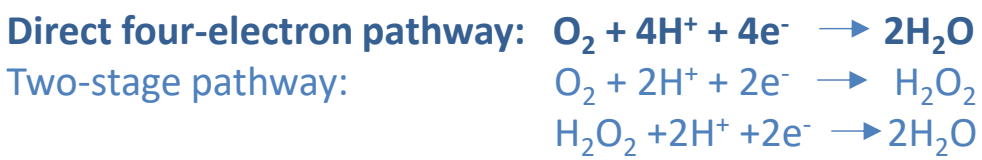

\section{Alkaline electrolyte}

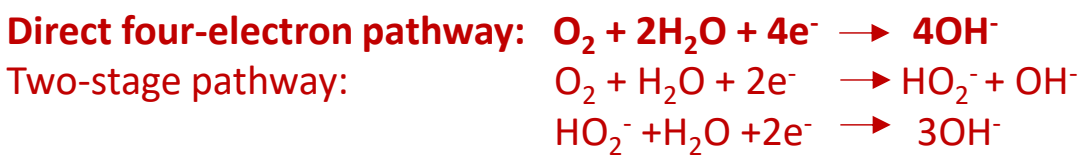

Scheme 1. Reaction pathways of oxygen reduction reaction in both acid and alkaline electrolytes

Highly dispersed metal catalysts, commonly platinum or platinum-based catalysts, supported on carbon-based materials, are used as electrocatalysts for oxidation and reduction reactions in PEMFCs fuelled with hydrogen or small organic molecules such as methanol or ethanol. The intrinsically high cost of Pt, however, is a serious roadblock in the large-scale roll-out of ORR-involving technologies since the catalyst (i.e. Pt) 
usually accounts to around $14 \%$ of the total cost [9]. This has led to a very high interest for inexpensive catalysts alternative to Pt (e.g. carbon and non-noble transition metals) that were introduced as either a supporting material or as an alloying element to reduce the usage of Pt [16-24].

In the past decade, the advances of nanotechnology and material science have opened new ways to develop novel electrocatalysts for fuel cells $[25,26]$. The use of nanomaterials in fuel cell systems can significantly improve the electrocatalytic performance to achieve high energy density and high power density while reducing the manufacturing cost. It is the aim of this article to review recent progress on nanostructured electrocatalysts for application to low temperature fuel cells, with the special attention on the contribution of our research teams in the advancement and study of electrocatalysts based on novel nanostructure carbons and noncarbon materials.

\section{Carbon-based nanomaterials as electrocatalysts supports}

Over past decades, carbon materials have been widely used as electrodes in low temperature fuel cells, not only because they have extraordinary physical properties such as high surface areas and good electronic conductivity, but also owing to their abundance, processibility and environmental friendliness [27-30].

In nature, carbon is found free in three main allotropic forms: amorphous carbon, graphite and diamond [31]. Depending on distinct types of crystal structures, carbon atoms can form a variety of allotropes endowed with different properties [27], as shown in Figure 2. The simplest graphite material is a two-dimensional "graphene" sheet, which is essentially a very large polyaromatic hydrocarbon. Graphite stands for typical $\mathrm{sp}^{2}$ hybridization. Diamond represents $\mathrm{sp}^{3}$ hybridized carbon materials exhibiting different electrochemical properties from $\mathrm{sp}^{2}$-related carbon materials. The most 
common fullerenes used as an electrode material are carbon nanotubes, which amount to single or multiple layer of graphene sheets "rolled up" to form tubes of varying diameter, length, and termination[32].

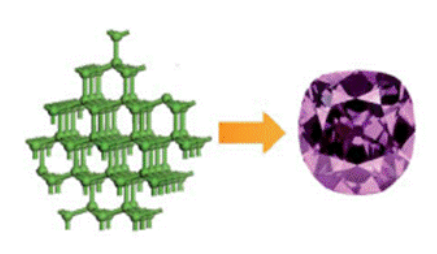

3D diamond

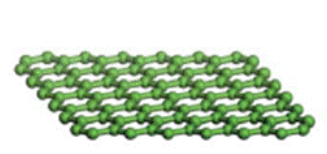

2D graphene
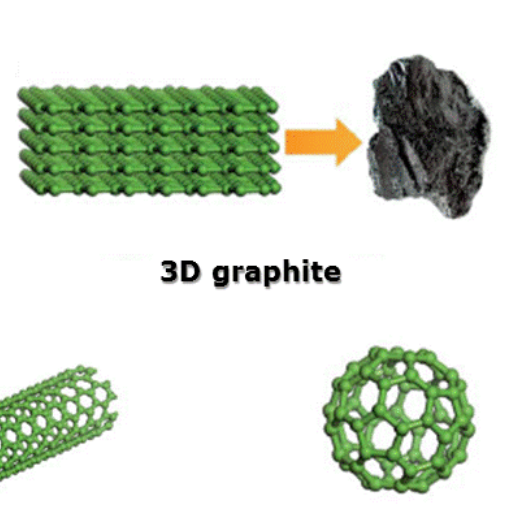

OD fullerene

Figure 2 Reproduced with permission from Ref [27] Copyright 2014, Royal Society of Chemistry

In general, $\mathrm{sp}^{2}$-hybridized carbon materials exhibit a high diversity in crystallinity, morphology, porosity and texture. These structural parameters play a crucial role in determining and optimizing the electrochemical performance when carbons are used as electrodes [33]. On the other hand, the completely $\mathrm{sp}^{3}$ hybridized, tetrahedral bonding of diamond results in both its hardness and low electrical conductivity, with the latter property making single- or polycrystalline diamond uninteresting as an electrode material. However, the introduction of heteroatomos, as boron or nitrogen, into diamond structure can increase the conductivity of diamond sufficiently to make electrodes with distinct electrochemical properties [32].

The conventional use of the carbon materials in fuel cells are mainly as catalyst supports for lowering the load of precious metals and enhancing the catalyst activity 
with prolonged catalyst durability. Some of the main characteristics of these carbon materials are described below.

\subsection{Carbon black}

Carbon black is obtained by pyrolyzing petroleum hydrocarbon. Highly conductive carbon blacks $(\mathrm{CBs})$ of turbostratic structures with high surface areas, such as Vulcan XC-72R (Cabot Corp, $250 \mathrm{~m}^{2} \mathrm{~g}^{-1}$ ) or Ketjen Black (KB EC600JD \& KB EC600J, Ketjen International, $1270 \mathrm{~m}^{2} \mathrm{~g}^{-1}$ and $800 \mathrm{~m}^{2} \mathrm{~g}^{-1}$, respectively) are commonly used as fuel cell electrocatalyst supports to ensure large electrochemical reaction surfaces and to reduce noble metal loading. $[27,34,35]$. Specially, Vulcan $\mathrm{XC}-72 \mathrm{R}$ has been proved to be a superior support since it has a relatively high specific surface area and passable electronic conductivity $[16,35,36]$.

The performance of the carbon blacks supported catalysts can be improved by different chemical and physical treatments. The wettability and adsorptive behaviour of a carbon, as well as its catalytic and its electrical properties, are influenced by the nature and extent of the oxygen complexes [37]. Our team studied the effect of the oxygenated surface groups of carbon support Vulcan $\mathrm{XC}-72 \mathrm{R}$ on the electrochemical properties of PtRu catalysts $[16,19,36,38]$. We revealed how the pre-treatment of carbon with oxidizing reagents $\left(\mathrm{HNO}_{3}, \mathrm{H}_{2} \mathrm{O}_{2}\right)$ improves the activity of the electrocatalyst in methanol electrooxidation. Carboxylic, phenolic, carbonyls, anhydrides, ethers, lactones and quinones were suggested as acidic surface groups produced by oxidation treatments. Surface oxygen complexes of the support exhibit an outstanding role in this field due to their double function: (a) they are anchorage sites for the metal precursor during catalyst preparation, and (b) they can act as active centres in multifunctional catalysts due to their acid-base or redox properties. An alternative to the oxidative pre- 
treatment of the support is the oxidative treatment of the supported metal catalyst. This was explored in ternary catalysts, such as the carbon (Vulcan $\mathrm{XC} 72 \mathrm{R}$ ) supported PtRuMo catalysts $[17,39]$. Oxidation with aqueous $\mathrm{H}_{2} \mathrm{O}_{2}$ during the preparation of catalysts mainly affected the atomic ratio of $\mathrm{Pt} / \mathrm{Mo}$ and increased the extent of oxidation of surface with no influence on the sample nanostructure. Futhermore, the presence of MoOx and a more oxidized surface of a treated carbon support avoids the bonding of $\mathrm{CO}$ to $\mathrm{PtRu}$ producing a $\mathrm{CO}$ tolerant catalyst that is more active for methanol electrooxidation. The presence of these oxophilic atoms in the surface alloy was also studied in the ethanol oxidation reaction [21]. In situ spectroelectrochemical studies were used to identity adsorbed reaction intermediates and products (in situ Fourier transform infrared spectroscopy, FTIR) and volatile reaction products (differential electrochemical mass spectrometry, DEMS). It was found that the higher ethanol oxidation current density on the PtRuMo/C catalyst with the higher amount of Mo results from higher yields of $\mathrm{C} 2$ products (acetaldehyde and acetic acid) and not from an improved complete ethanol oxidation to $\mathrm{CO}_{2}$ (Figure 3).

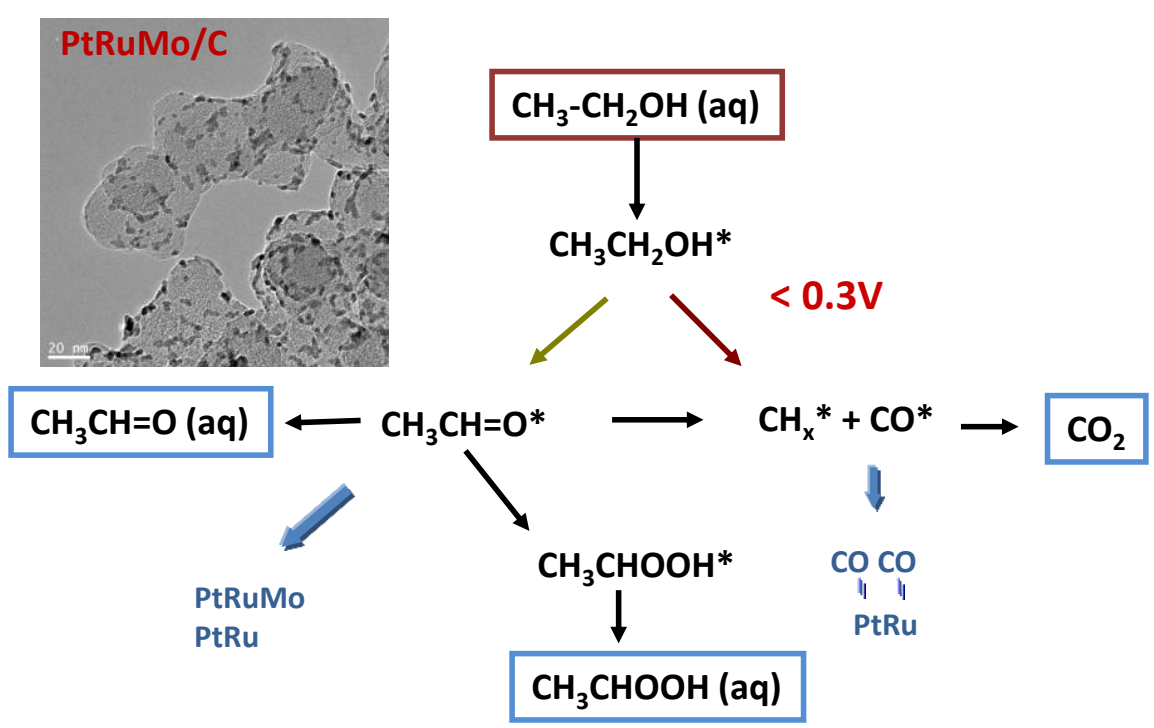

Figure 3 TEM image PtRuMo/C catalyst and schematic representation of a suggested mechanism of the electrochemical oxidation of ethanol on PtRuMo/C electrocatalysts 


\subsection{Mesoporous carbon}

Mesoporous carbon $(2 \mathrm{~nm}<$ pore sizes $<50 \mathrm{~nm})$ have incurred intense interest in fuel cell applications since they can facilitate the transport of reactants to the electrocalysts and simultaneously exhibit large surface areas and low charge-transfer resistance [40, 41]. Ordered mesoporous carbons (CMK-3) have received great attention due to their unique properties, they can find potential applications in several fields. They present a regular structure, high surface area, large pore volume and a narrow pore size distribution. Our group has previously studied CMK-3 carbons as supports in $\mathrm{Pt}$ electrocatalysts for fuel cells [42]. Before the platinum deposition, carbon support was functionalized using $\mathrm{HNO}_{3}$ as oxidizing agent to modify its surface chemistry. The characterization study of the electrocatalysts demonstrated that the surface chemistry of the support has an important effect on both the physicochemical and electrochemical properties of electrocatalysts. The Pt/CMK-3 based electrodes showed a better performance toward hydrogen oxidation than the commercial one, which could be attributed to the porous structure of the support. However, a major disadvantage of these materials is the low electrical conductivity, which hinders the charge transfer. This problem can be solved by graphitization of these carbon mesoporous carbons [43]. It was osbserved that under certain graphitisation conditions, the carbon corrosion of CMK-3 can be minimized showing lower rates compared to a commercial carbon black (Vulcan XC-72R).

\subsection{Carbon nanofibers}

Carbon nanofibers (CNFs) have attracted interest as electrocatalyst support due to their good compromise between textural and structural properties. These nanofibers can be obtained by the decomposition of carbon-containing gases, like methane or carbon 
monoxide, over small metallic particles as catalysts, typically metals of the iron subgroup. CNFs present unique textural properties, such as low content in micropores and impurities [22, 44]. Sebastian et al. [22] found that the functionalization of these carbon nanofibers increased about two times the surface oxygen content, which was needed to enhance Pt dispersion and anchorage. This functionalization influenced negatively on electrical conductivity and positively on oxidation resistance, whereas some other important properties like surface area or carbon crystallinity were hardly modified. Pt supported on the most conductive functionalized CNF support presented the highest current densities towards methanol electrooxidation, about two times higher than commercial catalyst (Pt/C ETEK). Tsiouvaras et al. [18] fabricated CNF-supported PtRuMoOx catalysts and examined their electroactivity for methanol oxidation reaction. The incorporation of MoOx and the nature of the CNF support affected considerably the performance in methanol electrooxidation, where electrochemical active area and metal nanoparticles stability during operation were key parameters.

\subsection{Carbon nanotubes}

Carbon nanotubes (CNTs) are generally categorized into single-walled carbon nanotubes (SWNTs), which consist of a single graphene sheet "rolled" into a tube, or multiwalled carbon nanotubes (MWNTs), which contain several concentric tubes sharing a common axis. In addition, MWNTs, can occur in various morphologies such as "hollow tube", "bamboo" and "herringbone", depending on their mode of preparation [32]. CNTs have drawn a great deal of attention as electrocatalyst support due to their unique geometric shape, excellent mechanical and thermal properties, high electric conductivity, large surface areas, and fascinating chemical stability [45]. For Hydrogen PEMFCs and DMFCs, it has been demonstrated that a CNT supported Pt catalyst 
exhibited better performance with respect to those supported by carbon black [31]. Furthermore, the high mechanical strength and superb corrosion-resistance of CNTs provide an excellent durability for ORR $[29,46]$.

\subsection{Carbon xerogels}

Carbon xerogels are attracting much attention for their unique and controllable properties, such as high surface area, mesopore structure with narrow pore size distribution, and high purity, which in turn, are attributed to the synthesis reaction mechanism, being similar to the sol-gel process. Their preparation, consisting on the polycondensation of resorcinol with formaldehyde followed by drying and pyrolysis, avoids supercritical drying required for the synthesis of carbon aerogels, offering great advantages in terms of cost and safety [47]. Besides, their three-dimensionally interconnected uniform pore structure allows a high degree of dispersion of the active phase and an efficient diffusion of reagents. Our team [47] synthesized Pt and PtRu electrocatalysts supported on functionalized xerogels. Results were compared to those obtained with commercial Pt/C and PtRu/C catalysts supported on Vulcan XC-72R (ETEK). All electrocatalysts supported on carbon xerogel showed better performances than commercial ones, providing higher current density values for the oxidation of methanol. Futhermore, the insertion of $\mathrm{S}$ into the mesoporous carbon xerogels was also studied in our laboratory [48]. It was observed that the insertion of S into the carbon matrix did not compromise their mesoporous structure. Pt catalysts supported on sulfurized carbon xerogels showed enhanced catalytic activity towards both the methanol electrooxidation and the oxygen electroreduction reactions, exceeding not only the performance of the catalyst supported on the bare xerogel, but also of the catalyst supported on a commercial carbon black (Figure 4). The sulfurization treatment 
was also effective in improving the resistance of the catalysts towards corrosion phenomena occurring at the fuel cell cathode.

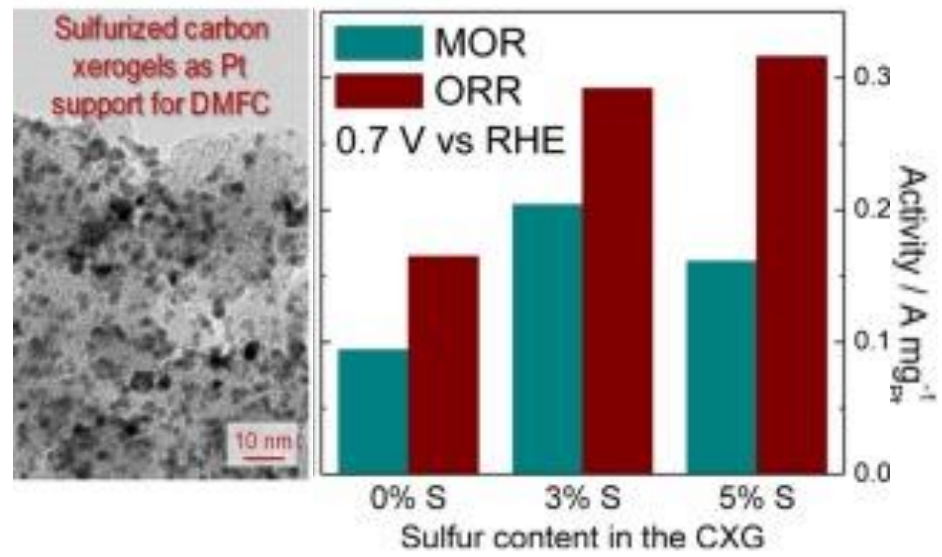

Figure 4 TEM image of sulfurized carbon xerogel supported Pt electrocatalyst and ORR and methanol oxidation reaction (MOR) mass activity at 0.7 V vs. RHE. Adapted from Ref. [48]

\subsection{Graphene}

Graphene is a two-dimensional (2D) crystal, composed of monolayer of carbon atoms arranged in a honeycombed network with six-membered rings [49]. As the fundamental 2D carbon structure, graphene can be conceptually viewed as an extended, 2D aromatic macromolecule, and can be also considered as a basic building block for carbon materials of all other dimensionalities including the wrapped $0 \mathrm{D}$ fullerenes, the rolled 1D nanotubes and the stacked 3D graphite (Figure 2) [27, 50, 51]. The combination of the high surface area, high conductivity, unique graphitized basal plane structure and potential low manufacturing cost makes graphene sheets a fascinating catalyst support in low-temperature fuel cells [52]. Typical fuel cell catalysts supported on graphene nanosheets (GNS) have been synthesized and characterized, and their electrocatalytic activity for chemical reactions of interest for an eventual use in fuel cells has been investigated by half-cell measurements and tests in single fuel cells have 
also been performed. Generally, using graphene sheets as a support very low metal particle size is obtained, lower than the particle size obtained by using other carbon supports. Low particle size is obtained also for high metal loadings on GNS. It is important to consider that the major component in graphene preparation is the graphene oxide (GO), which is commonly prepared by oxidizing graphite powder in severe chemical conditions. Oxygen-containing functional groups, including epoxy, carboxyl and hydroxyl, are then functionalized onto each side of the sheet $[53,54]$. The benefits of the use of GO as catalyst support are, consequently, further improved by its functionalization, giving rise to a higher and more homogeneous metal dispersion, which in turns increases the electrocatalytic activity. Moreover, the presence of oxygenand/or nitrogen-containing group on GNS surface, particularly on functionalized GNS surface, assists the oxidation of poisoning species adsorbed on the catalyst, coming to the partial oxidation of alcohols. Indeed, there is a general consensus regarding the effectiveness of the use of graphene-supported catalysts as anode materials in DMFCs. The catalytic activity for methanol oxidation of Me/GNS was always higher than that of $\mathrm{Me} / \mathrm{C}$ and/or Me/CNT [31, 52, 55-61]. However, controversial results regarding the activity for oxygen reduction of Me/GNS have been reported by half-cell measurements [52].

\section{Degradation of carbon supported electrocatalysts}

The long-term performance of fuel cells has become the most important challenge that currently needs to be addressed [62]. To compete with conventional internal combustion engines, a fuel cell should maintain at least $90 \%$ of its performance after $5000 \mathrm{~h}$ of operation (equivalent to 250000 kilometers), including thousands of start-up and shutdown events [63]. The lifetime of the fuel cells is limited by several factors, which are 
all interrelated and may act synergistically. The major problem regarding the use of carbon materials, especially carbon blacks, as fuel cell catalyst support and, particularly, as cathode catalyst support, is theirs low resistance to corrosion caused by electrochemical oxidation of the carbon surface. The oxidation of carbon to $\mathrm{CO}_{2}$, which is thermodynamically possible above $+0.207 \mathrm{~V}$ vs RHE, is kinetically limited below $+1.2 \mathrm{~V}$ RHE depending on the temperature [63]. In Figure 5 Mayrhofer group [64] provides a short summary of catalyst degradation mechanisms that have been suggested to occur in hydrogen fuel cells. Carbon corrosion has important consequences, as it can accelerate secondary degradation mechanisms such as agglomeration, Ostwald Rippening and particle detachment [65], while the associated loss of porosity can severely limit the mass transport of reactants and thus deteriorate the performance in the electrochemical reactor [66].

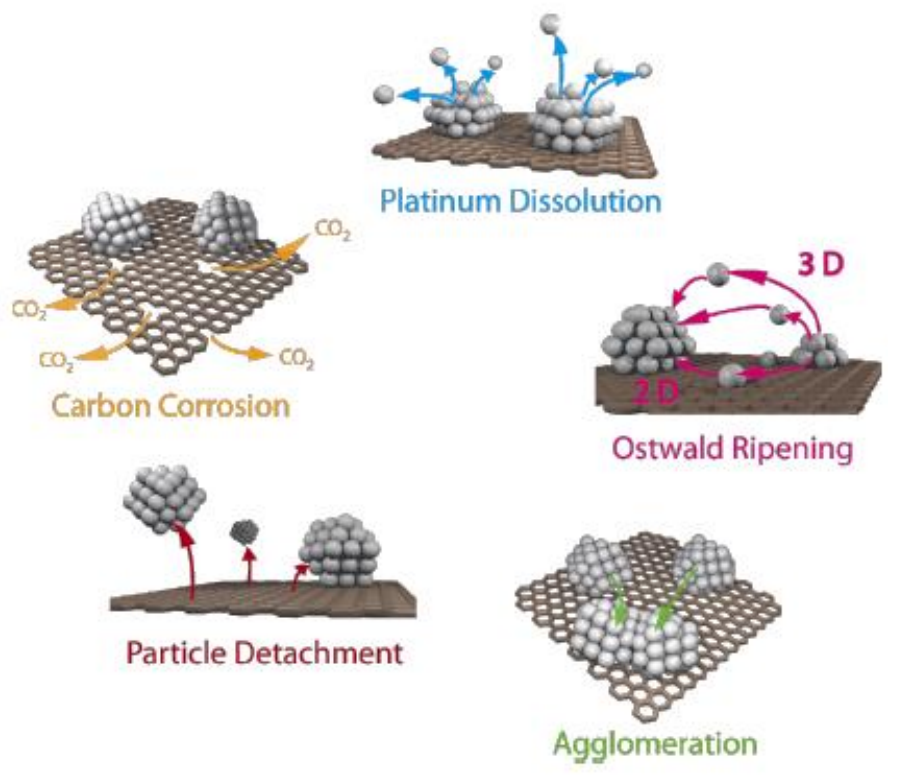

Figure 5 Simplified representation of suggested degradation mechanisms for $\mathrm{Pt}$ particles on a carbon support in fuel cells, from ref. [64]

Despite the considerable understanding of electrocatalyst and catalyst layer degradation mechanisms and the different implemented mitigation strategies on the 
materials site, one of the main challenges in the immediate future is to develop new electrocatalysts that improve the durability of the catalyst layer and also impact the electronic properties of the active phase to improved catalyst kinetics.

\section{Heteroatom-doped carbon catalysts}

Heteroatom doping is an effective approach to tailor the properties of carbon materials and extend their potential and stability in fuel cells. Specifically, doping carbon nanostructures with heteroatoms such as $\mathrm{N}, \mathrm{S}, \mathrm{B}, \mathrm{P}$ and/or F can substantially affect their electronic structures, chemical reactivity, $\mathrm{pH}$ as well as conductivity, and meanwhile maintain the intrinsic physical/chemical characteristics well [27]. As the size and electronegativity of the heteroatoms are different from those of carbon atom, the introduction of heteroatoms into carbon nanomaterials could cause electron modulation to change the charge distribution and electronic properties. This together with the doping-induced defects could further change the electrochemical activity of carbon nanomaterials, showing ORR activities in alkaline and acidic media [46, 67]. Therefore, the metal-free heteroatom-doped carbon nanomaterials are a new class of promising ORR electrocatalysts because they exhibit comparable or higher electrocatalytic activity and long-time stability compared to the commercial Pt/C electrocatalyst [68-71].

Among these heteroatoms, the nitrogen atom is the most popular atomic species used to dope the carbon framework since its atomic radius is close to that of the carbon atom $[11,72-76]$. The method used for the synthesis of nitrogen-doped carbon catalysts depends on the properties and type of carbon used as well as the desired properties of the final catalyst. The carbon materials include carbon blacks, carbon nanotubes, mesoporous carbon, carbon nanofibers and graphene. The methods for the $\mathrm{N}$ doping can generally be grouped in two categories, namely, direct growth and post-synthesis. In 
direct growth, the doping of carbon with nitrogen takes place during the synthesis of the carbon nanostructures. The post-synthetic approach involves treatment of carbon with a reactive nitrogen agent, for example, with a nitrogen plasma, ammonia gas or nitrogencontaining polymers [73]. Nitrogen-doped carbons essentially contain nitrogen incorporated in the carbon structure, either at the edges or within the core structure of the carbon material by replacing one of the $\mathrm{sp}^{2}$ hybridized carbon atoms in the graphitic structure.

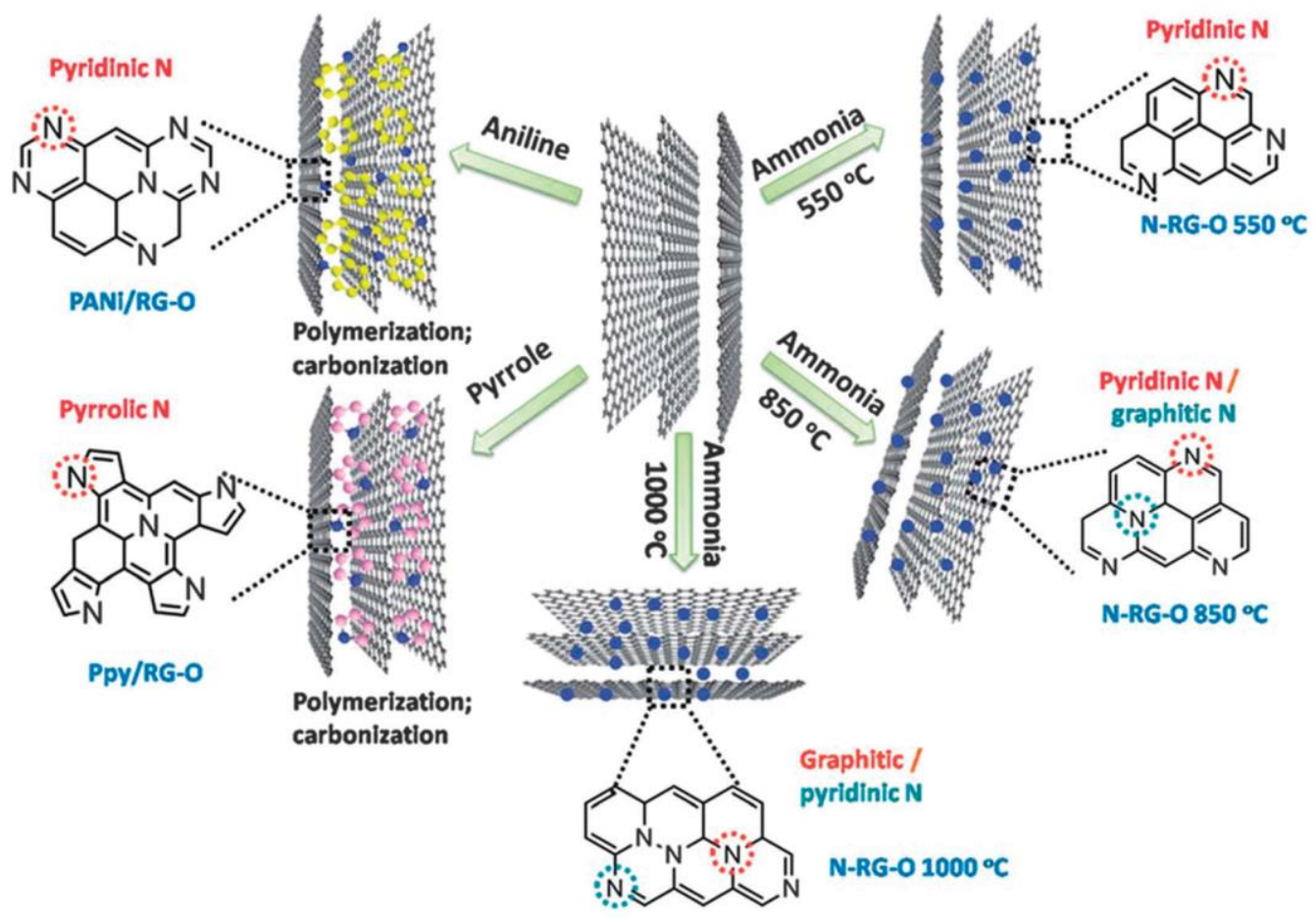

Figure 6 Reproduced with permission from Ref [77]. Copyright 2012, Royal Society of Chemistry

There is enormous research activity concerned with the development of nitrogenmodified carbons catalysts for the ORR. Figure 6 summarizes an example of the tailored synthesis of pyrrolic, pyridinic, and graphitic carbon reported by Lai et al.[77]. In particular, it was observed that annealing graphene oxide with ammonia preferentially formed graphitic and pyridinic nitrogen centers, while annealing a 
composite of polyaniline with reduced graphene oxide and polypyrrole with reduced graphene oxide tended to generate pyridinic and pyrrolic nitrogen moieties, respectively. Some authors claim that the graphitic species plays the dominant role [77], while others contend that the pyridinic species is more active and dominant [78].

\section{Noncarbon supported electrocatalysts}

An alternative strategy to address the stability issues of carbon-based materials is to use transition-metal oxides as supports. Typically, so-called Magnéli phases $\left(\mathrm{Ti}_{\mathrm{n}} \mathrm{O}_{2 \mathrm{n}-1}\right.$, on average $\mathrm{Ti}_{4} \mathrm{O}_{7}$ ), but also $\mathrm{WO}_{3}, \mathrm{NbO}_{2}, \mathrm{TaO}_{2}$, and $\mathrm{TiO}_{2}$ have been employed because of their remarkable stability under fuel-cell conditions, low cost, commercial availability, ease of control of the size and structure, and good dispersion of the catalyst. [79-81]. However, such oxides typically have low electronic conductivity, which has to be increased by producing oxygen vacancies or introducing an appropriate dopant. Therefore, research is also being pursued on materials based on transition metal carbide and nitride family for their application in low temperature fuel cells, as described in a review by Ham and Lee [82]. Titanium carbides and nitrides are well-known for its high melting point, high resistance to oxidation and corrosion, good thermal and electrical conductivity. Recently, our team reported the preparation of $\mathrm{TiC}, \mathrm{TiCN}$, and $\mathrm{TiN}$ supported Pt nanoparticles as anode materials for $\mathrm{CO}$ and methanol electrooxidation reactions in acidic and alkaline media. An electronic effect by the Ti-based support was observed, in which a considerably enhancement of the $\mathrm{CO}$ tolerance respect to carbonsupported catalysts was achieved [83]. Additionally, an effect of TiC and TiCN surface oxidation was reported (Figure 7A) [84]. It was observed that for electrochemically surface oxidized TiC and TiCN supported platinum catalysts (1.0 V vs RHE), the 
activity toward methanol oxidation was several fold higher than for unmodified $\mathrm{TiC}$ and TiCN supported catalysts and even higher than that achieved by a commercial PtRu/C ( Figure 7B).
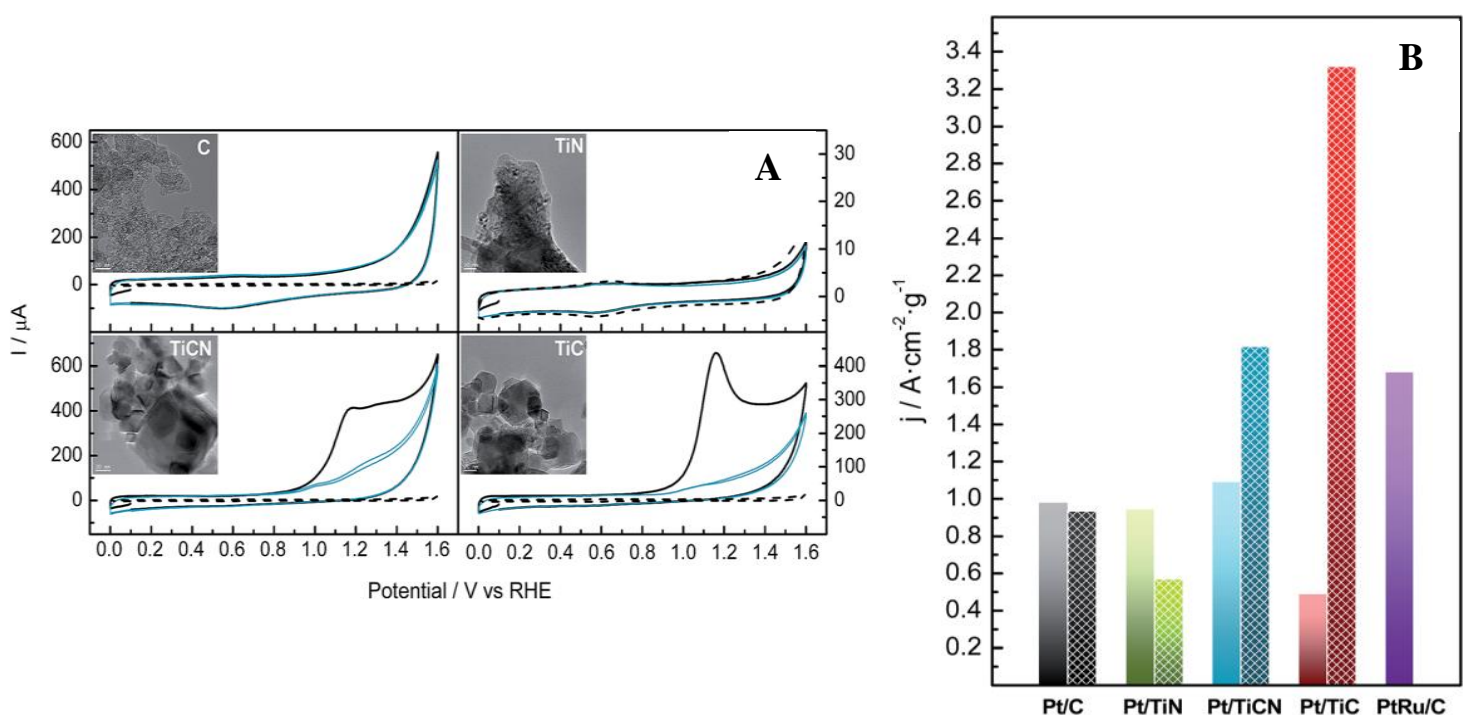

Figure 7 A) TEM images and cyclic voltammograms of $\mathrm{C}$, TiN, TiC and TiCN supports recorded in $0.5 \mathrm{M} \mathrm{H}_{2} \mathrm{SO}_{4}$. Scan rate: $20 \mathrm{mV} \mathrm{s}^{-1}$. B) Current density of $\mathrm{Pt} / \mathrm{C}, \mathrm{Pt} / \mathrm{TiC}, \mathrm{Pt} / \mathrm{TiCN}$, $\mathrm{Pt} / \mathrm{TiN}$ and PtRu/C (Johnson Mattey) recorded at $400 \mathrm{~s}$ in $2 \mathrm{M} \mathrm{CH}_{3} \mathrm{OH}+0.5 \mathrm{M} \mathrm{H}_{2} \mathrm{SO}_{4} . \mathrm{E}_{\mathrm{f}}=0.55$ V. Solid color: catalysts activated up to $0.9 \mathrm{~V}$. PtRu/C activated up to $0.8 \mathrm{~V}$. Stripped color: catalysts activated up to $1.0 \mathrm{~V}$.[84]

\section{Carbon-nanocomposites materials}

Nanocomposites are a special class of materials originating from suitable combinations of two or more nanosized objects in some suitable technique, resulting in materials having unique physical properties and wide potential application in diverse areas. Novel properties of nanocomposites can be derived from the successful combination of the characteristics of parent constituents into a single material $[85,86]$.

Antolini [87] reported an overview of the composite materials as low temperature fuel cell catalysts supports in 2010. In this comprehensive review the composite 
materials were classified into three major groups, polymer-carbon, ceramic-carbon and polymer-ceramic. All of them proved to posse more suitable properties for their use as catalyst supports than their individual components. For example, hybrid polymer-carbon supports presented higher accessible surface areas, higher electronic conductivity and easier charge-transfer at the polymer/electrolyte interface than the single matrix. The size of the metal nanoparticles deposited on the polymer-carbon composite matrix was commonly smaller than that on single polymer. This resulted in a higher dispersion and better utilization of the metal nanoparticle-impregnated composites. The higher catalyst dispersion, together with the enhanced properties of the hybrid support, resulted in a high performance of the composite-supported catalysts. Moreover, in the composite ceramic-carbon materials, the ceramic material supplied co-catalytic properties and increases the corrosion resistance, and the carbon supplied high electron conductivity to the mixed composite [87-91].

In the last years, the research on exploring the use of carbon nanocomposites as noble-metal free catalysts in fuel cells is growing rapidly. While carbon nanocomposites with good ORR activity in alkaline media can be prepared without any detectable metal content $[53,75,78,92-94]$, the presence of metal transitions, principally Fe and/or Co, has been found so far to generate catalysts with the highest activity and four-electron selectivity [77, 95-97]. Such superior performance would be attributed to the synergetic effect between carbon nanomaterials with a large surface area/stable structure and the transition metal-based nanoparticles with high ORR electrocatalytic activities [68]

One of the most interesting materials is the formation of polymer-carbon composites, using the polymer as a source of heteroatoms. The heteroatom-containing precursor method can achieve the in-situ homogeneous incorporation of heteroatom into carbonaceous materials, without pre- or post-processing. The vast majority of reports 
dealing with polymer materials involve the study of $\mathrm{N}$-containing polymers, most frequently polypyrrole (PPy) [77, 94, 98-103] and polyaniline (PAni) $[77,95,97,104-$ 107], but also biopolymer as chitosan [23, 108], and more recently polydopamine [109].

Conductive polypyrrole (PPy) presents good electrical conductivity, environmental and thermal stability, and the ease of preparation by chemical and electrochemical processes [98]. Due to the high gas diffusion and conduction properties of PPy, it results in a two-phase boundary that facilitates the electrochemical reaction. It is also an effective precursor for $\mathrm{N}$-doped carbon nanomaterials. Very recently, porous $\mathrm{N}$-doped carbon nanotubes were fabricated using PPy nanotubes as a precursor [99]. The resulting catalysts exhibited excellent electrocatalytic activity, through a four-electron pathway for the ORR in alkaline media. These catalysts exhibited more positive onset potentials, higher half-wave potentials, higher current densities and durability for ORR than those of a commercial Pt/C catalyst.

Polyaniline (PANI) is a conducting polymer of the semi-flexible rod polymer family, and represents a favorable combination of aromatic rings connected via nitrogencontaining groups. Because of the similarity between the structures of PANI and graphite, the heat treatment of PANI could facilitate the incorporation of nitrogencontaining active sites into the partially graphitized carbon matrix. Furthermore, the use of such a polymer as a nitrogen precursor promised a more uniform distribution of nitrogen sites on the surface and an increase in the active-site density $[95,105]$. Wu et al [107] prepared active and durable non-precious metal catalysts for the oxygen reduction reaction based on the heat treatment of polyaniline/Co or Fe/carbon precursors. They observed that the use of cobalt in the synthesis leads to much lower activity than the use of iron, where the polymer was predominately transformed into graphitized structures. 
Chitosan is a very abundant, nontoxic and low cost biopolymer, constituted of glucosamine and acetylglucosamine monomers, which has good complexing ability due to the presence of $-\mathrm{OH}$ and $-\mathrm{NH}_{2}$ groups on the chain [23]. Chitosan has been recently chosen as both carbon and $\mathrm{N}$ sources due to its abundant $\mathrm{N}$-bearing groups and the possible self-organization of the carbon species into graphene-like carbon nanosheets during carbonization [110-115]. Recently, Qiao et al [112] have prepared Graphene/nitrogen-doped porous carbon sandwiches for the metal-free oxygen reduction reaction using chitosan as nitrogen source. Nitrogen doping leads to an increased electrical conductivity due to electron excess in the delocalized $\pi$-system. Thus, the electrical conductivity and the number and the nature of the active sites were two important factors determining the performance of nitrogen-doped carbons in the ORR.

Polydopamine (PDA) is non-toxic and biocompatible polymer. PDA is an ecofriendly, bio-inspired mussel adhesive molecule that is generated by self-polymerization of dopamine, which forms a thin film on various substrates without any surface pretreatment [116]. The presence of nitrogen groups in PDA increases the electrical conductivity and, at the same time, enhances the electron affinity of the catalytic sites to facilitate adsorption of an oxygen molecule, which weakens the strong oxygen-oxygen double bond. Parnell et al. [109] have synthetized an Mn(III) catalyst supported on graphene and further coated with polydopamine, resulting in superior ORR activity compared to the uncoated PDA structures. The materials reduced oxygen in a wide $\mathrm{pH}$ range via a four-electron pathway.

Other fascinating noble metals-free materials are composites composed of both carbon based nanostructures and ceramic nanoparticles enveloped within the graphitic layers. During the past five years, the interest for this type of materials has grown 
exponentially. By introducing carbon nanomaterials with different dimensions and even heteroatom dopants into transition metal carbides or nitrides nanoparticles, it is possible to obtain higher activity and stability in low temperature fuel cells compared to their unsupported counterparts $[10,68,101$, 117-120]. Recently, chromium nitride nanoparticles supported on graphitic carbon nanocapsules containing carbon nitride have been synthesized by a solvothermal-assisted ion-exchange route. As a Pt-free catalyst, the composite exhibited superior activity, stability and a dominant 4-electron pathway towards oxygen reduction reaction [117]. Another facile and cost-effective strategy has been the preparation of iron carbide nanoparticles encapsulated in mesoporous $\mathrm{Fe}-\mathrm{N}$-doped graphene-like carbon composites. The catalyst exhibited excellent catalytic activity toward ORR and high catalytic efficiency and long-term durability, which was even comparable with the state-of-the-art Pt/C catalyst [118]. Mesoporous material ordered mesoporous carbon/tungsten carbide was prepared and used as electrocatalyst for methanol electro-oxidation [120]. These composites showed good electrocatalytic property close to that of the Pt-based materials for methanol oxidation. Therefore, the interesting and powerful synergetic effect between the carbon nanomaterials with large surface area/stable structure and the transition metal carbide or nitride nanoparticles can lead to a superior electrocatalytic performance and durability for low temperature fuel cells.

\section{Summary}

This article review progress in the research and development of electrocatalysts for low temperature fuel cells technologies, with especial attention in the contribution of our research teams over the last 15 years or so. The intensive research efforts in reducing or replacing Pt-based electrodes in fuel cells have been focus in the use of 
carbon nanomaterials as electrocatalytic supports, including carbon nanostructures tailored by surface modification or building in particular dopants/defects. Recent research effort has also led to the use of electronic conductivity noncarbon support materials. However, heteroatom-doped carbon nanomaterials have been recently discovered as a new class of metal-free electrocatalysts, which, as alternative ORR catalysts, could dramatically reduce the cost and increase the efficiency of fuel cells. In addition, carbon-composite materials are proving to be a robust, inexpensive and active electrocatalysts, where the synergetic effect between the carbon nanomaterials with large surface area/stable structure and the ceramic or polymer nanostructures can lead to a superior electrocatalytic performance and durability for low temperature fuel cells. Continued research in this exciting field will surely transform the way in which future energy systems are developed and should result in better fuel economy and a decrease in hamful emissions.

\section{Acknowledges}

Authors thank the Ministry of Economy and Competitiveness (MINECO) and FEDER through the Project ENE2014-52158-C2-1-R for financial support.

\section{References}

[1] Y.-J. Wang, N. Zhao, B. Fang, H. Li, X.T. Bi, H. Wang, Carbon-Supported PtBased Alloy Electrocatalysts for the Oxygen Reduction Reaction in Polymer Electrolyte Membrane Fuel Cells: Particle Size, Shape, and Composition Manipulation and Their Impact to Activity, Chemical Reviews, 115 (2015) 3433-3467.

[2] H.A. Gasteiger, N.M. Markovi-ç, Just a Dream-or Future Reality?, Science, 324 (2009) 48-49. 
[3] M.E. Scofield, H. Liu, S.S. Wong, A concise guide to sustainable PEMFCs: recent advances in improving both oxygen reduction catalysts and proton exchange membranes, Chemical Society Reviews, 44 (2015) 5836-5860.

[4] M.V. Martinez-Huerta, G. Garcia, Fabrication of electrocatalytic nanoparticles and applications to PEMFCs, in: D.Y.C. Leung, J. Xuan (Eds.) Micro and NanoEngineering of Fuel Cells, CRC Press2015, pp. 95-115.

[5] O.Z. Sharaf, M.F. Orhan, An overview of fuel cell technology: Fundamentals and applications, Renewable and Sustainable Energy Reviews, 32 (2014) 810-853.

[6] H.W. Zhang, D.Z. Chen, Y. Xianze, S.B. Yin, Anion-Exchange Membranes for Fuel Cells: Synthesis Strategies, Properties and Perspectives, Fuel Cells, 15 (2015) 761-780.

[7] E.H. Yu, X. Wang, U. Krewer, L. Li, K. Scott, Direct oxidation alkaline fuel cells: from materials to systems, Energy \& Environmental Science, 5 (2012) 5668-5680.

[8] Q. Li, R. Cao, J. Cho, G. Wu, Nanocarbon Electrocatalysts for Oxygen Reduction in Alkaline Media for Advanced Energy Conversion and Storage, Advanced energy materials, 4 (2014) 1301415.

[9] A. Brouzgou, A. Podias, P. Tsiakaras, PEMFCs and AEMFCs directly fed with ethanol: a current status comparative review, Journal of Applied Electrochemistry, 43 (2013) 119-136.

[10] D. Higgins, P. Zamani, A. Yu, Z. Chen, The application of graphene and its composites in oxygen reduction electrocatalysis: a perspective and review of recent progress, Energy \& Environmental Science, 9 (2016) 357-390.

[11] W. Yang, T.P. Fellinger, M. Antonietti, Efficient Metal-Free Oxygen Reduction in Alkaline Medium on High-Surface-Area Mesoporous Nitrogen-Doped Carbons Made from Ionic Liquids and Nucleobases, Journal of the American Chemical Society, 133 (2010) 206-209.

[12] J. Zhang, H. Li, P. Guo, H. Ma, X.S. Zhao, Rational design of graphitic carbon based nanostructures for advanced electrocatalysis, Journal of Materials Chemistry A, 4 (2016) 8497-8511.

[13] W. Vielstich, A. Lamm, H.A. Gasteiger, Handbook of Fuel cells-Fundamentals, Technology and Applications, Wiley (2003) 302.

[14] G. Hoogers, Fuel cell Technology Handbook, Chapter 6 (2003).

[15] H.A. Gasteiger, S.S. Kocha, B. Sompalli, F.T. Wagner, Activity benchmarks and requirements for Pt, Pt-alloy, and non-Pt oxygen reduction catalysts for PEMFCs, Appl.Catal.B: Environ., 56 (2005) 9-35. 
[16] J.L. Gómez de la Fuente, M.V. Martínez-Huerta, S. Rojas, P. Terreros, J.L.G. Fierro, M.A. Peña, Enhanced methanol electrooxidation activity of PtRu nanoparticles supported on $\mathrm{H}_{2} \mathrm{O}_{2}$-functionalized carbon black., Carbon, 43 (2005) 3002-3005.

[17] M.V. Martínez-Huerta, J.L. Rodríguez, N. Tsiouvaras, M.A. Peña , J.L.G. Fierro, E. Pastor, Novel synthesis method of CO-tolerant PtRu-MoOx nanoparticles: structural characteristics and performance for methanol electrooxidation, Chem.Mater., 20 (2008) 4249-4259.

[18] N. Tsiouvaras, M.V. Martínez-Huerta, R. Moliner, M.J. Lazaro, J.L. Rodriguez, E. Pastor, M.A. Peña, J.L.G. Fierro, CO tolerant PtRu-MoOx nanoparticles supported on carbon nanofibers for direct methanol fuel cells, J Power Sources, 186 (2009) 299-304.

[19] J.L. Gómez de la Fuente, M.V. Martínez-Huerta, S. Rojas, P. HernándezFernández, P. Terreros, J.L.G. Fierro, M.A. Peña Tailoring and structure of PtRu nanoparticles supported on functionalized carbon for DMFC applications: New evidence of the hydrous ruthenium oxide phase, Appl.Catal.B: Environ., 88 (2009) 505514.

[20] V. Celorrio, L. Calvillo, M.V. Martínez-Huerta, R. Moliner, M.J. Lałüzaro, Study of the Synthesis Conditions of Carbon Nanocoils for Energetic ApplicationsGÇá, Energy \& Fuels, 24 (2010) 3361-3365.

[21] G. García, N. Tsiouvaras, E. Pastor, M.A. Peña, J.L.G. Fierro, M.V. MartínezHuerta, Ethanol oxidation on PtRuMo/C catalysts: In situ FTIR spectroscopy and DEMS studies, International Journal of Hydrogen Energy, 37 (2012) 7131-7140.

[22] D. Sebastián, J.C. Calderón, J.A. González-Expósito, E. Pastor, M.V. MartínezHuerta, I. Suelves, R. Moliner, M.J. Lázaro, Influence of carbon nanofiber properties as electrocatalyst support on the electrochemical performance for PEM fuel cells, International Journal of Hydrogen Energy, 35 (2010) 9934-9942.

[23] B. Aghabarari, M.V. Martínez-Huerta, M. Ghiaci, J.L.G. Fierro, M.A. Peña, Hybrid chitosan derviative-carbon support for oxygen reduction reactions, RSC Adv., 3 (2013) 5378-5381.

[24] M. Liu, R. Zhang, W. Chen, Graphene-supported nanoelectrocatalysts for fuel cells: Synthesis, properties, and applications, Chemical Reviews, 114 (2014) 51175160.

[25] Y. Qiao, C.M. Li, Nanostructured catalysts in fuel cells, Journal of Materials Chemistry, 21 (2011) 4027-4036. 
[26] Z. Peng, H. Yang, Designer platinum nanoparticles: Control of shape, composition in alloy, nanostructure and electrocatalytic property, Nano Today, 4 (2009) 143-164.

[27] H. Huang, X. Wang, Recent progress on carbon-based support materials for electrocatalysts of direct methanol fuel cells, Journal of Materials Chemistry A, 2 (2014) 6266-6291.

[28] G. Girishkumar, K. Vinodgopal, P.V. Kamat, Carbon nanostructures in portable fuel cells: Single-walled carbon nanotube electrodes for methanol oxidation and oxygen reduction, Journal of Physical Chemistry B, 108 (2004) 19960-19966.

[29] D.-W. Wang, D. Su, Heterogeneous nanocarbon materials for oxygen reduction reaction, Energy \& Environmental Science, 7 (2014) 576-591.

[30] Y. Shao, J. Liu, Y. Wang, Y. Lin, Novel catalyst support materials for PEM fuel cells: current status and future prospects, Journal of Materials Chemistry, 19 (2009) 4659.

[31] L. Dai, D.W. Chang, J.-B. Baek, W. Lu, Carbon Nanomaterials for Advanced Energy Conversion and Storage, Small, 8 (2012) 1130-1166.

[32] R.L. McCreery, Advanced Carbon Electrode Materials for Molecular Electrochemistry, Chemical Reviews, 108 (2008) 2646-2687.

[33] D.S. Su, R. Schlögl, Nanostructured Carbon and Carbon Nanocomposites for Electrochemical Energy Storage Applications, ChemSusChem, 3 (2010) 136-168.

[34] S. Sharma, B.G. Pollet, Support materials for PEMFC and DMFC electrocatalysts: A review, Journal of Power Sources, 208 (2012) 96-119.

[35] E. Antolini, Carbon supports for low temperature fuel cell catalysts, Appl.Catal.B: Environ., 88 (2009) 1-24.

[36] J.L. Gómez de la Fuente, S. Rojas, M.V. Martínez-Huerta, P. Terreros, M.A. Peña , J.L.G. Fierro, Functionalization of carbon support and its influence on the electrocatalytic behaviour of $\mathrm{Pt} / \mathrm{C}$ in $\mathrm{H}_{2}$ and $\mathrm{CO}$ electrooxidation, Carbon, 44 (2006) 1919-1929.

[37] S. Rojas, M.V. Martínez-Huerta, M.A. Peña Supported metals for application in Fuel Cells, Supported Metals in Catalysis.Imperial College Press.London, (2012).

[38] J.L. Gómez de la Fuente, M.V. Martínez-Huerta, S. Rojas, P. Terreros, J.L.G. Fierro, M.A. Peña, Methanol electrooxidation on PtRu nanoparticles supported on functionalised carbon black, Catal.Today, 116 (2006) 422-432.

[39] N. Tsiouvaras, M.V. Martínez-Huerta, O. Paschos, U. Stimming, J.L.G. Fierro, M.A. Peña, PtRuMo/C catalysts for direct methanol fuel cells: Effect of the 
pretreatment on the structural characteristics and methanol electrooxidation, International Journal of Hydrogen Energy, 35 (2010) 11478-11488.

[40] G. Alvarez, F. Alcaide, O. Miguel, L. Calvillo, M.J. Lázaro, J. Quintana, J. Calderon, E. Pastor, Technical electrodes catalyzed with PtRu on mesoporous ordered carbons for liquid direct methanol fuel cells, Journal of Solid State Electrochemistry, 14 (2010) 1027-1034.

[41] L. Calvillo, M.J. Lazaro, E. Garcia-Bordeje, R. Moliner, P.L. Cabot, I. Esparbe, E. Pastor, J.J. Quintana, Platinum supported on functionalized ordered mesoporous carbon as electrocatalyst for direct methanol fuel cells, J Power Sources, 169 (2007) 59-64.

[42] L. Calvillo, M. Gangeri, S. Perathoner, G. Centi, R. Moliner, M.J. Lázaro, Synthesis and performance of platinum supported on ordered mesoporous carbons as catalyst for PEM fuel cells: Effect of the surface chemistry of the support, International Journal of Hydrogen Energy, 36 (2011) 9805-9814.

[43] V. Celorrio, D. Sebastián, L. Calvillo, A.B. García, D.J. Fermin, M.J. Lázaro, Influence of thermal treatments on the stability of Pd nanoparticles supported on graphitised ordered mesoporous carbons, International Journal of Hydrogen Energy, 41 (2016) 19570-19578.

[44] P. Serp, M. Corrias, P. Kalck, Carbon nanotubes and nanofibers in catalysis, Appl.Catal.A-Gen., 253 (2003) 337-358.

[45] W. Zhang, S. Ravi, P. Silva, Application of carbon nanotubes in polymer electrolyte based fuel cells, Reviews on Advanced Materials Science, 29 (2011) 1-14.

[46] L. Dai, Y. Xue, L. Qu, H.-J. Choi, J.-B. Baek, Metal-Free Catalysts for Oxygen Reduction Reaction, Chemical Reviews, 115 (11) (2015) 4823-4892.

[47] C. Alegre, L. Calvillo, R. Moliner, J.A. González-Expósito, O. Guillén-Villafuerte, M.V. Martínez-Huerta, E. Pastor, M.J. Lázaro, Pt and PtRu electrocatalysts supported on carbon xerogels for direct methanol fuel cells, Journal of Power Sources, 196 (2011) 4226-4235.

[48] C. Alegre, D. Sebastián, M.E. Gálvez, R. Moliner, M.J. Lázaro, Sulfurized carbon xerogels as Pt support with enhanced activity for fuel cell applications, Applied Catalysis B: Environmental, 192 (2016) 260-267.

[49] K.S. Novoselov, A.K. Geim, S.V. Morozov, D. Jiang, Y. Zhang, S.V. Dubonos, I.V. Grigorieva, A.A. Firsov, Electric Field Effect in Atomically Thin Carbon Films, Science, 306 (2004) 666-669.

[50] A.K. Geim, K.S. Novoselov, The rise of graphene, Nat Mater, 6 (2007) 183-191. 
[51] D. Chen, L. Tang, J. Li, Graphene-based materials in electrochemistry, Chemical Society Reviews, 39 (2010) 3157-3180.

[52] E. Antolini, Graphene as a new carbon support for low-temperature fuel cell catalysts, Appl.Catal.B: Environ., 123-124 (2012) 52-68.

[53] G. Wu, A. Santandreu, W. Kellogg, S. Gupta, O. Ogoke, H. Zhang, H.-L. Wang, L. Dai, Carbon nanocomposite catalysts for oxygen reduction and evolution reactions: From nitrogen doping to transition-metal addition, Nano Energy, 29 (2016) 83-110.

[54] W. Gao, G. Wu, M.T. Janicke, D.A. Cullen, R. Mukundan, J.K. Baldwin, E.L. Brosha, C. Galande, P.M. Ajayan, K.L. More, A.M. Dattelbaum, P. Zelenay, Ozonated graphene oxide film as a proton-exchange membrane, Angewandte Chemie International Edition, 53 (2014) 3588-3593.

[55] L. Dong, R.R.S. Gari, Z. Li, M.M. Craig, S. Hou, Graphene-supported platinum and platinum-ruthenium nanoparticles with high electrocatalytic activity for methanol and ethanol oxidation, Carbon, 48 (2010) 781-787.

[56] Y. Li, W. Gao, L. Ci, C. Wang, P.M. Ajayan, Catalytic performance of Pt nanoparticles on reduced graphene oxide for methanol electro-oxidation, Carbon, 48 (2010) 1124-1130.

[57] S. Sharma, A. Ganguly, P. Papakonstantinou, X. Miao, M. Li, J.L. Hutchison, M. Delichatsios, S. Ukleja, Rapid Microwave Synthesis of CO Tolerant Reduced Graphene Oxide-Supported Platinum Electrocatalysts for Oxidation of Methanol, The Journal of Physical Chemistry C, 114 (2010) 19459-19466.

[58] Y.G. Zhou, J.J. Chen, F.b. Wang, Z.H. Sheng, X.H. Xia, A facile approach to the synthesis of highly electroactive Pt nanoparticles on graphene as an anode catalyst for direct methanol fuel cells, Chemical Communications, 46 (2010) 5951-5953.

[59] D.A.C. Brownson, D.K. Kampouris, C.E. Banks, An overview of graphene in energy production and storage applications, Journal of Power Sources, 196 (2011) 4873-4885.

[60] Y. Sun, Q. Wu, G. Shi, Graphene based new energy materials, Energy \& Environmental Science, 4 (2011) 1113-1132.

[61] H. Wu, D. Wexler, H. Liu, Durability investigation of graphene-supported Pt nanocatalysts for PEM fuel cells, Journal of Solid State Electrochemistry, 15 (2011) 1057-1062.

[62] R. Borup, J. Meyers, B. Pivovar, Y.S. Kim, R. Mukundan, N. Garland, D. Myers, M. Wilson, F. Garzon, D. Wood, P. Zelenay, K. More, K. Stroh, T. Zawodzinski, J. 
Boncella, J.E. McGrath, M. Inaba, K. Miyatake, M. Hori, K. Ota, Z. Ogumi, S. Miyata, A. Nishikata, Z. Siroma, Y. Uchimoto, K. Yasuda, K. Kimijima, N. Iwashita, Scientific Aspects of Polymer Electrolyte Fuel Cell Durability and Degradation, Chemical Reviews, 107 (2007) 3904-3951.

[63] I. Katsounaros, S. Cherevko, A.R. Zeradjanin, K.J.J. Mayrhofer, Oxygen Electrochemistry as a Cornerstone for Sustainable Energy Conversion, Angewandte Chemie International Edition, 53 (2014) 102-121.

[64] J.C. Meier, C. Galeano, I. Katsounaros, J. Witte, H.J. Bongard, A.A. Topalov, C. Baldizzone, S. Mezzavilla, F. Schüth, K.J.J. Mayrhofer, Design criteria for stable Pt/C fuel cell catalysts, Beilstein Journal of Nanotechnology, 5 (2014) 44-67.

[65] J.C. Meier, C. Galeano, I. Katsounaros, A.A. Topalov, A. Kostka, F. Schüth, K.J.J. Mayrhofer, Degradation Mechanisms of Pt/C Fuel Cell Catalysts under Simulated StartStop Conditions, ACS Catalysis, 2 (2012) 832-843.

[66] H. Schulenburg, B. Schwanitz, N. Linse, G.ê.G. Scherer, A. Wokaun, J. Krbanjevic, R. Grothausmann, I. Manke, 3D Imaging of Catalyst Support Corrosion in Polymer Electrolyte Fuel Cells, The Journal of Physical Chemistry C, 115 (2011) 14236-14243.

[67] A. Rabis, P. Rodriguez, T.J. Schmidt, Electrocatalysis for Polymer Electrolyte Fuel Cells: Recent Achievements and Future Challenges, ACS Catalysis, 2 (2012) 864-890.

[68] M. Zhou, H.-L. Wang, S. Guo, Towards high-efficiency nanoelectrocatalysts for oxygen reduction through engineering advanced carbon nanomaterials, Chemical Society Reviews, 45 (2016) 1273-1307.

[69] S. Gao, X. Wei, H. Fan, L. Li, K. Geng, J. Wang, Nitrogen-doped carbon shell structure derived from natural leaves as a potential catalyst for oxygen reduction reaction, Nano Energy, 13 (2015) 518-526.

[70] W. Li, D. Yang, H. Chen, Y. Gao, H. Li, Sulfur-doped carbon nanotubes as catalysts for the oxygen reduction reaction in alkaline medium, Electrochimica Acta, 165 (2015) 191-197.

[71] M. Seredych, K. László, E. Rodríguez-Castellón, T.J. Bandosz, S-doped carbon aerogels/GO composites as oxygen reduction catalysts, Journal of Energy Chemistry, 25 (2016) 236-245.

[72] C. Tang, Q. Zhang, Can metal-nitrogen-carbon catalysts satisfy oxygen electrochemistry?, Journal of Materials Chemistry A, 4 (2016) 4998-5001. 
[73] J. Masa, W. Xia, M. Muhler, W. Schuhmann, On the Role of Metals in NitrogenDoped Carbon Electrocatalysts for Oxygen Reduction, Angewandte Chemie International Edition, 54 (2015) 10102-10120.

[74] Y. Sun, C. Li, G. Shi, Nanoporous nitrogen doped carbon modified graphene as electrocatalyst for oxygen reduction reaction, Journal of Materials Chemistry, 22 (2012) 12810-12816.

[75] K. Gong, F. Du, Z. Xia, M. Durstock, L. Dai, Nitrogen-Doped Carbon Nanotube Arrays with High Electrocatalytic Activity for Oxygen Reduction, Science, 323 (2009) 760-764.

[76] T. Maiyalagan, Synthesis and electro-catalytic activity of methanol oxidation on nitrogen containing carbon nanotubes supported Pt electrodes, Appl.Catal.B: Environ., 80 (2008) 286-295.

[77] L. Lai, J.R. Potts, D. Zhan, L. Wang, C.K. Poh, C. Tang, H. Gong, Z. Shen, J. Lin, R.S. Ruoff, Exploration of the active center structure of nitrogen-doped graphene-based catalysts for oxygen reduction reaction, Energy \& Environmental Science, 5 (2012) 7936-7942.

[78] T. Xing, Y. Zheng, L.H. Li, B.C.C. Cowie, D. Gunzelmann, S.Z. Qiao, S. Huang, Y. Chen, Observation of Active Sites for Oxygen Reduction Reaction on NitrogenDoped Multilayer Graphene, ACS Nano, 8 (2014) 6856-6862.

[79] E. Antolini, E.R. Gonzalez, Ceramic materials as supports for low-temperature fuel cell catalysts, Solid State Ionics, 180 (2009) 746-763.

[80] C.-P. Lo, G. Wang, A. Kumar, V. Ramani, TiO2-RuO2 electrocatalyst supports exhibit exceptional electrochemical stability, Applied Catalysis B: Environmental, 140141 (2013) 133-140.

[81] Z. Zhang, J. Liu, J. Gu, L. Su, L. Cheng, An overview of metal oxide materials as electrocatalysts and supports for polymer electrolyte fuel cells, Energy \& Environmental Science, 7 (2014) 2535-2558.

[82] D.J. Ham, J.S. Lee, Transition metal carbides and nitrides as electrode materials for low temperature fuel cells, Energies, 2 (2009) 873-899.

[83] M. Roca-Ayats, G. García, J.L. Galante, M.A. Peña, M.V. Martínez-Huerta, TiC, TiCN, and TiN Supported Pt Electrocatalysts for CO and Methanol Oxidation in Acidic and Alkaline Media, The Journal of Physical Chemistry C, 117 (2013) 20769-20777.

[84] M. Roca-Ayats, G. Garcia, M.A. Pena, M.V. Martinez-Huerta, Titanium carbide and carbonitride electrocatalyst supports: modifying Pt-Ti interface properties by 
electrochemical potential cycling, Journal of Materials Chemistry A, 2 (2014) 1878618790.

[85] R. Gangopadhyay, A. De, Conducting Polymer Nanocomposites: A Brief Overview, Chemistry of Materials, 12 (2000) 608-622.

[86] P. Gomez-Romero, Hybrid Organic-Inorganic Materials-In Search of Synergic Activity, Advanced Materials, 13 (2001) 163-174.

[87] E. Antolini, Composite materials: An emerging class of fuel cell catalyst supports, Appl.Catal.B: Environ., 100 (2010) 413-426.

[88] D.L. Boxall, G.A. Deluga, E.A. Kenik, W.D. King, C.M. Lukehart, Rapid Synthesis of a Pt1Ru1/Carbon Nanocomposite Using Microwave Irradiation: A DMFC Anode Catalyst of High Relative Performance, Chem.Mater., 13 (2001) 891-900.

[89] E.S. Steigerwalt, G.A. Deluga, D.E. Cliffel, C.M. Lukehart, A Pt-Ru/graphitic carbon nanofiber nanocomposite exhibiting high relative performance as a directmethanol fuel cell anode catalyst, Journal of Physical Chemistry B, 105 (2001) 80978101.

[90] E.S. Steigerwalt, G.A. Deluga, C.M. Lukehart, Pt-Ru/carbon fiber nanocomposites: Synthesis, characterization, and performance as anode catalysts of direct methanol fuel cells. A search for exceptional performance, Journal of Physical Chemistry B, 106 (2002) 760-766.

[91] J.T. Moore, J.D. Corn, D. Chu, R. Jiang, D.L. Boxall, E.A. Kenik, C.M. Lukehart, Synthesis and Characterization of a Pt3Ru1/Vulcan Carbon Powder Nanocomposite and Reactivity as a Methanol Electrooxidation Catalyst, Chem.Mater., 15 (2003) 33203325 .

[92] J. Liu, P. Song, Z. Ning, W. Xu, Recent Advances in Heteroatom-Doped MetalFree Electrocatalysts for Highly Efficient Oxygen Reduction Reaction, Electrocatalysis, 6 (2015) 132-147.

[93] Z.K. Yang, L. Lin, Y.-N. Liu, X. Zhou, C.-Z. Yuan, A.-W. Xu, Supramolecular polymers-derived nonmetal N, S-codoped carbon nanosheets for efficient oxygen reduction reaction, Rsc Advances, 6 (2016) 52937-52944.

[94] P. Ting, L. Hongying, R. Guangyuan, L. Yunan, L. Xianyong, Z. Ying, Metal-free porous nitrogen-doped carbon nanotubes for enhanced oxygen reduction and evolution reactions, Science Bulletin, 61 (2016) 889. 
[95] G. Wu, K.L. More, C.M. Johnston, P. Zelenay, High-Performance Electrocatalysts for Oxygen Reduction Derived from Polyaniline, Iron, and Cobalt, Science, 332 (2011) 443-447.

[96] Q. Liu, J. Zhang, Graphene Supported Co-g- $\mathrm{C}_{3} \mathrm{~N}_{4}$ as a Novel Metal-Macrocyclic Electrocatalyst for the Oxygen Reduction Reaction in Fuel Cells, Langmuir, 29 (2013) 3821-3828.

[97] Z.-s. Yin, T.-h. Hu, J.-l. Wang, C. Wang, Z.-x. Liu, J.-w. Guo, Preparation of highly active and stable polyaniline-cobalt-carbon nanotube electrocatalyst for oxygen reduction reaction in polymer electrolyte membrane fuel cell, Electrochimica Acta, 119 (2014) 144-154.

[98] E. Das, A.B. Yurtcan, Effect of carbon ratio in the polypyrrole/carbon composite catalyst support on PEM fuel cell performance, International Journal of Hydrogen Energy, 41 (2016) 13171-13179.

[99] T. Pan, H. Liu, G. Ren, Y. Li, X. Lu, Y. Zhu, Metal-free porous nitrogen-doped carbon nanotubes for enhanced oxygen reduction and evolution reactions, Science Bulletin, 61 (2016) 889-896.

[100] W. Li, W. Ding, G. Wu, J. Liao, N. Yao, X. Qi, L. Li, S. Chen, Z. Wei, Cobalt modified two-dimensional polypyrrole synthesized in a flat nanoreactor for the catalysis of oxygen reduction, Chemical Engineering Science, 135 (2015) 45-51.

[101] L. Gu, L. Jiang, J. Jin, J. Liu, G. Sun, Yolk-shell structured iron carbide/N-doped carbon composite as highly efficient and stable oxygen reduction reaction electrocatalyst, Carbon, 82 (2015) 572-578.

[102] A. Morozan, P. Jegou, S. Campidelli, S. Palacin, B. Jousselme, Relationship between polypyrrole morphology and electrochemical activity towards oxygen reduction reaction, Chemical Communications, 48 (2012) 4627-4629.

[103] Q. Liu, Z. Pu, C. Tang, A.M. Asiri, A.H. Qusti, A.O. Al-Youbi, X. Sun, N-doped carbon nanotubes from functional tubular polypyrrole: A highly efficient electrocatalyst for oxygen reduction reaction, Electrochemistry Communications, 36 (2013) 57-61.

[104] U. Byambasuren, Y. Jeon, D. Altansukh, Y.-G. Shul, Doping effect of boron and phosphorus on nitrogen-based mesoporous carbons as electrocatalysts for oxygen reduction reaction in acid media, Journal of Solid State Electrochemistry, 20 (2016) 645-655.

[105] G. Wu, P. Zelenay, Nanostructured Nonprecious Metal Catalysts for Oxygen Reduction Reaction, Accounts of Chemical Research, 46 (2013) 1878-1889. 
[106] Z. Lin, G.H. Waller, Y. Liu, M. Liu, C.-p. Wong, Simple preparation of nanoporous few-layer nitrogen-doped graphene for use as an efficient electrocatalyst for oxygen reduction and oxygen evolution reactions, Carbon, 53 (2013) 130-136.

[107] G. Wu, C.M. Johnston, N.H. Mack, K. Artyushkova, M. Ferrandon, M. Nelson, J.S. Lezama-Pacheco, S.D. Conradson, K.L. More, D.J. Myers, P. Zelenay, Synthesisstructure-performance correlation for polyaniline-Me-C non-precious metal cathode catalysts for oxygen reduction in fuel cells, Journal of Materials Chemistry, 21 (2011) 11392-11405.

[108] M. El Achaby, Y. Essamlali, N. El Miri, A. Snik, K. Abdelouahdi, A. Fihri, M. Zahouily, A. Solhy, Graphene oxide reinforced chitosan/polyvinylpyrrolidone polymer bio-nanocomposites, Journal of Applied Polymer Science, 131 (2014) 41402.

[109] C.M. Parnell, B. Chhetri, A. Brandt, F. Watanabe, Z.A. Nima, T.K. Mudalige, A.S. Biris, A. Ghosh, Polydopamine-Coated Manganese Complex/Graphene Nanocomposite for Enhanced Electrocatalytic Activity Towards Oxygen Reduction, Scientific Reports, 6 (2016) 31415.

[110] T.X. Wu, G.Z. Wang, X. Zhang, C. Chen, Y.X. Zhanga, H.J. Zhao, Transforming chitosan into N-doped graphitic carbon electrocatalysts, Chemical Communications, 51 (2015) 1334-1337.

[111] X.B. Liu, I.S. Amiinu, S.J. Liu, K. Cheng, S.C. Mu, Transition metal/nitrogen dual-doped mesoporous graphene-like carbon nanosheets for the oxygen reduction and evolution reactions, Nanoscale, 8 (2016) 13311-13320.

[112] M. Qiao, C. Tang, G. He, K. Qiu, R. Binions, I.P. Parkin, Q. Zhang, Z. Guo, M.M. Titirici, Graphene/nitrogen-doped porous carbon sandwiches for the metal-free oxygen reduction reaction: conductivity versus active sites, Journal of Materials Chemistry A, 4 (2016) 12658-12666.

[113] M.K. Rybarczyk, M. Lieder, M. Jablonska, N-doped mesoporous carbon nanosheets obtained by pyrolysis of a chitosan-melamine mixture for the oxygen reduction reaction in alkaline media, Rsc Advances, 5 (2015) 44969-44977.

[114] Z.Y. Wu, P. Chen, Q.S. Wu, L.F. Yang, Z. Pan, Q. Wang, Co/Co3O4/C-N, a novel nanostructure and excellent catalytic system for the oxygen reduction reaction, Nano Energy, 8 (2014) 118-125.

[115] S.L. Xie, S.C. Huang, W.J. Wei, X.Z. Yang, Y. Liu, X.H. Lu, Y.X. Tong, Chitosan Waste-Derived Co and N Co-doped Carbon Electrocatalyst for Efficient Oxygen Reduction Reaction, Chemelectrochem, 2 (2015) 1806-1812. 
[116] J. Liebscher, R. Mrówczyński, H.A. Scheidt, C. Filip, N.D. Hădade, R. Turcu, A. Bende, S. Beck, Structure of Polydopamine: A Never-Ending Story?, Langmuir, 29 (2013) 10539-10548.

[117] L. Zhao, L. Wang, P. Yu, D. Zhao, C. Tian, H. Feng, J. Ma, H. Fu, A chromium nitride/carbon nitride containing graphitic carbon nanocapsule hybrid as a Pt-free electrocatalyst for oxygen reduction, Chemical Communications, 51 (2015) 1239912402 .

[118] H. Jiang, Y. Yao, Y. Zhu, Y. Liu, Y. Su, X. Yang, C. Li, Iron Carbide Nanoparticles Encapsulated in Mesoporous Fe-N-Doped Graphene-Like Carbon Hybrids as Efficient Bifunctional Oxygen Electrocatalysts, Acs Applied Materials \& Interfaces, 7 (2015) 21511-21520.

[119] X. Fan, Z. Peng, R. Ye, H. Zhou, X. Guo, M3C (M: Fe, Co, Ni) Nanocrystals Encased in Graphene Nanoribbons: An Active and Stable Bifunctional Electrocatalyst for Oxygen Reduction and Hydrogen Evolution Reactions, ACS Nano, 9 (2015) 74077418.

[120] H. Zheng, Z. Chen, Y. Li, C.a. Ma, Synthesis of ordered mesoporous carbon/tungsten carbides as a replacement of platinum-based electrocatalyst for methanol oxidation, Electrochimica Acta, 108 (2013) 486-490. 